\title{
Mongolian Color Preference and Architectural Color Expression
}

\author{
Nan $\mathrm{Li}^{1,}$ a , Songhua $\mathrm{Gao}^{2, \mathrm{~b}}$, Jie Ren ${ }^{1, \mathrm{c}}$ \\ ${ }^{1}$ Office of college of architecture, Inner Mongolia University of Technology, Hohhot, Inner Mongolia \\ 010051, China \\ ${ }^{2}$ Office of college of international modern design art, Inner Mongolia Normal University, Hohhot, \\ Inner Mongolia 010052, China \\ an80_622@163.com, bgaosonghua@imnu.edu.cn, 467586457@qq.com
}

Keywords: Mongolian, color preference, architectural color

Abstract. The grassland region is a multi-ethnic area mainly composed of Mongolian. Because of economic and cultural interactions and influences among different ethnic groups, there are long history and tradition. At the same time, the northern nations are also impacted by Tibetan Buddhism and the Central Plains culture, creating a unique color culture. The paper summarizes the Mongolian preference of several major colors and on the basis of color preference, further elaborates its architectural features in several forms of expressions, including the architectural color under natural condition, color in architectural decorative pattern and architectural color in temple culture. Finally, put forwards renewal problems and ideas in modern Mongolian architectural color applications.

\section{Introduction}

The vitality of a city has a close and inevitable connection with the excavation, preservation, inheritance and promotion of its urban context. "Urban context is the lifestyle that forms during the birth and evolution of a city and the historical mark that survives at different stages. The urban context is an integral part of urban character and an important symbol of the distinction among cities" [1]. The urban context covers the urban history, culture, politics, economy and other elements, along with the urban form, urban color and other contents to express the urban mechanism and urban humanity. Among them, the urban color also shows its characteristic and important value in the form of "context".

We should fully collate the color context and analyze the evolution mechanism of color context, so that can proactively inherit, continue and renewal the urban system to maximize the realization of urban value and practical significance. For Inner Mongolia Autonomous Region located in the Northwest minority area, many urban development histories contain unique ethnic cultural resources. How to excavate the urban ethnic characteristics and promote its regional culture is very urgent and the exploration of "color context" is undoubtedly one of the direction. The expressions of color context are diverse and complex, as colors are attached to every urban aspect, such as urban road, architectural surface, sign, signboard, but color preference and identification are consistent with ideology.

\section{Mongolian Color Preference}

The grassland region is a multi-ethnic area mainly composed of Mongolian. Because of the economic and cultural interactions and influences among different ethnic groups, there are long history and tradition. At the same time, the northern nations are also impacted by Tibetan Buddhism and the Central Plains culture, creating a unique color culture. In general, the colors present a bright and gorgeous feeling and a sense of excitement. These colors are more symbolic and decorative on the basis of realistic colors. To sum up, the most representative basic colors revered and loved by Mongolian are white, blue, red three colors, in addition, gold and silver are also very popular.

White Color. It is called "Chagan" in Mongolian. In the eyes of Mongolian, white is one of the most beautiful and auspicious colors. In folk, white is closely related to people's live. For diet, people like to 
eat "Chagan Yide", that is "white food", dairy products. For clothing, people like to wear white leather coat. For housing, people are often proud to live in a new white Mongolian yurt [2].

Blue Color. Blue is the color of Mongolian. It is called "Hoh" in Mongolian, Hohhot in Mongolian means blue city. In the eyes of Mongolian, blue symbolizes eternity, faithfulness and loyalty. When Mongolian ancestors first established the country, they once called the country "Blue Mongolia", the imperial palace was called "Blue Palace", and the national history book was called "Blue Book" etc. In life, in all kinds of decorative patterns and architectural paintings, blue color is also used more common.

Red Color. Red is called "Wulan" in Mongolian [3]. Mongolian worship fire and believe in the Fire God and Kitchen God, deeming the fire, Fire God or Kitchen God is holy to drive away the evil spirits and demons. It is believed that the fire with its red light shining on the earth, giving warmth to people. In Mongolian real life, red is also used a lot, boxes with red background to draw color patterns, felt curtains, camel saddles, felt carpets, wrestling clothes are decorated with red cloth collage patterns.

Gold and Silver Colors. Mongolian believe that gold is a beautiful color, it can represent all the basic colors. Since the Ming and Qing dynasties, gold and silver color edges are used often in Mongolian folk art. When the adjacent color contrast is too weak, plain, vague, or the contrast is too strong, contradicting and conflicting, gold and silver colors are used as isolation to clarify the chaotic color relationship and harmonize the provoking color relationship, this method of color reconciliation is called isolation reconciliation. Relying on the innate instinct of colors, Mongolian are excellent in gold and silver color applications.

\section{Mongolian Traditional Architectural Decorative Color}

Mongolian Architectural Color under Natural Condition. Mongolian architecture art follows the artistic tradition in the northern grassland climatic condition. A large amount of color paintings on architectures come from the humanity art, but it cannot be ignored that there is a certain temporal and spatial connection between the basic colors of the architecture and its natural environment. With no one's consciousness effect, the hue selection, tone combinations etc. are combined with the environmental colors to achieve the harmony and unity.

The elevation of Inner Mongolia is high, about 1000-1200 m, because of the strong ultraviolet intensity and high light intensity, the light condition makes the architecture surface color fade easily. Therefore, it makes the hue selection tend to be strong, rich in color elements, and high purity colors are boldly used. Under the natural condition of significant light change, the colors at places exposed to longer light time will fade seriously, but the protection of backlight surface is better and the color preservation degree is higher, therefore, it will naturally form a contrast effect.

The understanding of this natural phenomenon is helpful to the application and research of modern Mongolian architectural color. There are many natural factors like these, such as in the vast grassland, there are long distance between Mongolian yurts of nomadic households, this geographical condition determines the color selection of white to Mongolian yurts to increase visibility in some extent. Therefore, the natural condition is one of the determinant factors that cannot be ignored in Mongolian traditional architectural color applications.

Color in Architectural Decorative Pattern. National pattern plays a huge role in the ancient Mongolian architectural art. Folk patterns such as folk painting, embroidery art, wood carving, metal engraving, pottery and sculpture art also appear in the same or similar forms in architecture. For example, for the eaves decoration of the temple architecture, in addition to the Tibetan architectural and Ming and Qing dynasties palace style pattern, the most important feature is that it has many fine patterns of Mongolian folk patterns, such as cloud, circle, phoenix, dragon, brocade, embroidery, flower and plant patterns, with rich and colorful colors, especially the cloud and circle patterns are widely used.

For the famous Mongolian mobile architecture - Mongolia yurt, the pattern on top of the roof of the Mongolian yurts is normally the cloud pattern, representing holy white clouds, which is a symbol of 
strength, auspiciousness and nationality, expressing the feeling of Mongolian nature worship. In the book of "Mongol Jewelry", Martha Boyer mentions that there are lots of Hamuer, that is the Mongol cloud pattern, is used in Mongolian decorations, especially used in edge decorations [4]. The application of cloud pattern determines its color selection, therefore, the cloud pattern around the top of the yurts is basically a combination of blue and white, which come from the natural simple colors of blue sky and white cloud; for circle pattern, it is often seen at the four corners of the roof of modern architecture. This pattern is the ancient Mongolian traditional pattern, because of its continuous pattern feature, representing the endless expectations of the nation. The circle pattern is more abstract and more colorful. Single color of circle pattern is used on some modern Mongolian architectures, some use light gray color which is a little lighter than the roof brightness, focusing on the overall color coordination, while others use yellow, brown and other means of color highlighting to stress the national color charm. This kind of color emphasizing ideas is integrated naturally with traditions. For yurt, wealthy people will decorate the door upper edge with flower patterns with the method of applique, and the patterns are usually bright red, very eye-catching, showing the infinite imagination of Mongolian, expressing the best wishes and beautiful longings of the owners; the interior decorative colors are more prominent, all indoor conspicuous wooden frames, ceilings, pillars, rafters, doors etc. are dyed red.

From a number of cases we have seen that the study of national pattern is of great significance to the summary of national color. It is found in the complex Mongolian patterns that first, the tone selection depends on the theme of the pattern, generally follows the design theme in nature's real existence, such as keeping consistent color with flower color; second, auspicious expression of decorative pattern is not only through pattern, also rely on color psychological emotion to convey the best wishes; third, the color of decorative pattern is continued on architecture and the social factors such as rank and time cannot be ignored

Mongolian Architectural Color in Temple Culture. In Inner Mongolia, cities based on temples, or cities which are the combination of cities and temples in the history are not unusual, such as Hohhot and Baotou. It is found from the historical materials of the temple architectures in these cities that the color applications of such architectures meet certain standard requirements. Temple color is generally divided into two parts, the central temples and the remote temples. The central temples have the golden-brown temple roofs and yellow walls. The remote temples have dark gray roofs and red walls. However, due to the integration of Tibetan Buddhism and Mongolian culture in Inner Mongolia in the history, the temple architectural color in Inner Mongolia has increased the proportion of the grey red color since the late Ming and Qing dynasties. Especially colors on the pillar of wooden architectures, also affected by the Central Plains color culture, basically are red. It is worth noting that to avoid the Central Plains Royal red, it was changed to deep red. Such temples generally have strong and vivid visual expressions, and indirectly affects the colors of the architectural forms around the temples, such as residential architectures and trade fairs, resulting in the appearance of colorful cities in the history of Inner Mongolia. But it cannot be said that all architectures have such phenomenon. In the Ming and Qing dynasties, temples flourished, but the residential architectures still used adobes and other materials, without extra colors, retaining the original soil yellow color of adobes. Only the cities relative to the Central Plains region, due to a large number of temples, for example, in the Ming and Qing dynasties, there were nearly 400 temples in Hohhot, the overall colors of the city are relatively rich.

\section{Renewal of Mongolian Traditional Color}

In the 21st century, Inner Mongolia Autonomous Region has put forward the strategy of development the cultural area, relying on the excavation of regional ethnic cultural resources to take the characteristic brand strategy and build the brand city. As an important branch of national culture, Mongolian color is relying on modern design to achieve more scientific research and practice in renewal, and try to blend and integrate national culture with the world culture. Under the conditions of 
modern construction and development in Mongolia, the architectural color still shows its important significance. Its importance also lies in the scientific restoration of ancient architecture, the preservation of symbolism in modern architecture and so on.

The issue of color renewal is based on the innovation of the modern science and technology, contemporary aesthetic consciousness, construction and implementation methods, color function cognition, etc. to keep thinking about new issues in research. For example, people often have a misconception and common understanding of Mongolian traditional colors, thinking that the Mongolian traditional color applications whether in clothing or architecture, all belongs to the strong color decorations based on basic color, original color or pure color. However, With the aid of color research systems such as the practical color coordinate system of Japan and the Munsell color system of America, through the acquisition and positioning technology, can extend the more refined multiple color elements on the basis of retaining the authenticity of national colors. There are possibilities to have more abundant color expressions through color differences. This is the color renewal under the social background of modern color research and technological progress.

On the other hand, the deeper meaning of color renewal is beyond the principle application of color matching, thus should judge from the psychological induction caused by it to judge whether it can resonate in the hearts of the nation. The designed color that can blend naturally with the life of the nation is the color of the nation. Therefore, there is no fixed and unchanging national color tradition. The color renewal should be determined by modern personality and modern aesthetic. Mongolian color is both the content and form, also external and internal expressions. The renewal strategy should firmly grasp the external performance and internal motivation and combine the both together to deepen the color construction.

\section{Acknowledgements}

This work was financially supported by the Inner Mongolia Autonomous Region Department of Education Project of Research on Analysis and Application of Mongolian Interior Design Style Features in Cultural Assimilation in Inner Mongolia, China (2016030359).

\section{References}

[1] W. Bian: Research on Sustainable Development of Urban Color Based on New Contextual-ism. Doctoral Thesis of Tianjin University (2015), p. 82

[2] Q. Gu: Mongolian Traditional Aesthetic View and Development Trend. Art and Design (Theory Edition) (2011), p. 55

[3] P. Wang, X. Zhang: Investigation and Analysis of Mongolian National Characteristics of Urban Landscape in Xilinhaote. Journal of Inner Mongolia Agricultural University (Natural Science Edition) (2017), p. 11

[4] Y. Wu: Analysis of Cloud and Hamuer Patterns. Art Science and Technology (2016), p. 241 